\title{
Philosophical Conceptual Analysis as an Experimental Method
}

\author{
Michael T. Stuart
}

\begin{abstract}
Philosophical conceptual analysis is an experimental method. Focusing on this helps to justify it from the skepticism of experimental philosophers who follow Weinberg, Nichols \& Stich (2001). To explore the experimental aspect of philosophical conceptual analysis, I consider a simpler instance of the same activity: everyday linguistic interpretation. I argue that this, too, is experimental in nature. And in both conceptual analysis and linguistic interpretation, the intuitions considered problematic by experimental philosophers are necessary but epistemically irrelevant. They are like variables introduced into mathematical proofs which drop out before the solution. Or better, they are like the hypotheses that drive science, which do not themselves need to be true. In other words, it does not matter whether or not intuitions are accurate as descriptions of the natural kinds that undergird philosophical concepts; the aims of conceptual analysis can still be met.
\end{abstract}

Experimental philosophers have called into question the use of intuitions in philosophical conceptual analysis, which is claimed to be a cornerstone of traditional philosophical methodology. They argue that intuitions about philosophical concepts are unreliable because we cannot calibrate them against the world. What this or that group of people think of justice, is not necessarily what justice is. We need a way for conceptual analysis to make contact with the object of study-and bringing our culturally-indoctrinated and unstable intuitions into reflective equilibrium is not the way. Philosophy, it is claimed, is most reliable when it operates like science: collecting empirical data, testing hypotheses, and formalizing empirical generalities into mathematical relationships. Perhaps conceptual analysis should be left behind. 
One reason this conclusion is mistaken is that conceptual analysis is already quite scientific. Science is a refinement of our normal thinking patterns with its roots going all the way back to child's play (see for example, Cook, Goodman \& Schulz 2011). Why think that conceptual analysis, a refined version of other linguistic practices, is divorced from those same proud origins? Imre Lakatos argued that all of mathematics is nothing more than a series of conceptual reformations, which produces better and better definitions of mathematical concepts by a never-ending onslaught of counterexamples (1976). For Lakatos, this process is at once a mental, linguistic, and community activity and it achieves some epistemic good. Mathematics is thought to yield certainty, and plays an indispensable role in physical science. Perhaps philosophical conceptual analysis can be legitimated in a similar way, if philosophy plays an indispensable role in science as well. Yet this is not the argument I want to make. Rather, I argue that conceptual analysis in philosophy is a dynamic process which can be defended epistemologically because of important features it shares not with mathematics, but with the scientific method.

Conceptual analysis can be defined functionally. One of its goals is to specify the extension of a concept. For example, what does justice refer to? Part of this is finding properties common to all or most instances of a concept, or outlining relationships between the extensions or intensions of concepts. For example, are all the instances of water instances of $\mathrm{H}_{2} \mathrm{O}$ ? Are electrons only to be found in the context of an atom? Another goal that is somewhat independent of the last few is specifying the "normative profile" (or normative characteristics) of a concept. This goal asks what should be the extension of a concept, or its relation to other concepts. A successful conceptual analysis of knowledge should therefore reveal which things count as known, what it is about them that makes them known (for example, as opposed to only believed), how known things relate to true things, and so on. But also, such an analysis must tell us what should count as known, what should be the relation between the known and the true, and so on. The difference between conceptual analysis in philosophy on the one hand, and science on the other, is that the normative profiles of scientific concepts (for example, quark) can be quite thin. Determining their extensions and conceptual relations are often more important than sketching their normative profiles. Asking what quark should refer to is a sensible question, but in practice it is less central to scientific research than finding the properties common to quarks and 
the relations between quarks and other physical-theoretical entities. A different emphasis is often found in philosophical conceptual analysis, wherein normative considerations predominate. However, the difference is only one of degree.

One important motivation of Meaning, Frames, and Conceptual Representation is to push interdisciplinary boundaries, and considering conceptual analysis as an experimental method takes this motivation seriously because it brings together evidence from the study of language, cognitive science and philosophy of science. I argue that in both conceptual analysis and scientific inquiry we form hypotheses and then "test" them. The literature on scientific experiment is massive (for example, Ackermann 1985, Batens \& Van Bendegem 1988, Bogen \& Woodward 1988, Cartwright 1983, Collins \& Pinch 1993, Franklin 1986, 1990, 2002, Galison 1987, 1997, Gooding 1990, Gooding et al. 1989, Hacking 1983, Latour \& Woolgar 1986, Pickering 1985, Pinch 1986). Yet aside from a few German Idealists, very few have written about experimenting with concepts as linguistic entities (see Fehige \& Stuart 2014). After presenting the problem from experimental philosophy in more detail, I look at conceptual experimentation from two sides. First, I examine some relevant literature from cognitive science as an attempt to describe the mechanisms at work in conceptual experimentation. Second, I propose a preliminary account that attempts to defend the epistemological status of conceptual analysis conceived as a type of experimental linguistic interpretation.

\section{Experimental philosophy and skepticism about conceptual analysis}

Weinberg, Nichols, and Stich helped found a sub-discipline in philosophy with their 2001 paper, "Normativity and Epistemic Intuitions." In it, they identified a type of philosophical strategy they called "Epistemic Romanticism." Accounts that employ this strategy, like Plato's, rely on the premise that conceptual knowledge, for example, knowledge of the Forms, is already implanted in us, and we may extract it in dialogue. Weinberg, Nichols and Stich call the family of theories that work this way "Intuition Driven Romanticism," since they consider shared intuitions as evidence for a kind of innate, a priori knowledge.

For these authors and many of those who followed them (for example, Alexander et al. 2010, Knobe \& Nichols 2008, Machery et al. 2004, Mallon et al. 2009, Swain et al. 2008, Weinberg et al. 2006), an intuition is simply a spontaneous 
judgment about the properties of some case for which the agent may not be able to offer any plausible justification. Intuition Driven Romanticism takes intuitions as data, and then produces normative epistemic claims that are dependent on the intuitions used, at least in part. That is, if the input were different, the output would also be different (in proportion to the change in the input). Two examples they give of Intuition Driven Romanticism are reflective equilibrium (see Goodman 1955) and Alvin Goldman's “justificatory rules” (see Goldman 1986:60).

Thus, some group of cognitive agents might have intuitions and belief-formation processes that are different from those of western philosophers, and when they run their intuitions through their chosen method (for example, reflective equilibrium) they will emerge with different epistemic norms. The question is: how can we decide which set of norms to follow? There is no answer that is not also subject to objections about relativity, so the whole process is misguided. Epistemic norms will be relative to different cultures, socio-economic classes, and even the number of philosophy courses taken. And it is argued that such intuition-relativity does in fact exist. Here is a famous example of the type of evidence presented.

A scenario called "the Trutemp Case" is presented to survey volunteers. The case consists of the following report: A child on a deserted island gets hit on the head by a coconut, and as a result knows the exact temperature all the time, but does not know that he has this power. The survey volunteers are asked: when the child says, "It is 30 degrees Celsius," does he know this, or does he only believe it? Apparently, East Asian people are more likely than Westerners to say that a person so affected only believes their temperature guess. However, if you say instead that a team of scientists secretly tinkered with the boy's brain to cause this ability, the situation reverses and East Asian people become more likely than Westerners to report that the boy knows what he says. And finally, if you also say that many other people in the boy's community were secretly given the ability to tell the temperature, and then ask the knowledge question about a single member's belief about the temperature, East Asians are even more likely to attribute knowledge. The Westerners keep their judgments essentially constant over all these changes. The conclusion drawn is that the relation between a person and their community affects the epistemological status of their beliefs, but only if you are East Asian. 
In another well-known example, a Gettier case is presented to different cultural groups with each group providing consistently different responses. A standard case is about my friend who thinks George has an American car. In fact, just yesterday George traded in his Buick for a Pontiac (which is still American), so my friend says something true, and justified, when she says "George has an American car." Now, when asked if my friend knows the above statement, more East Asians than Westerners respond in the affirmative.

Weinberg, Nichols and Stich conclude that intuition-based analyses only provide information about the people who participate in them, and not any mindindependent truths about the referents of philosophical concepts. Unfortunately, mind-independent truths are precisely what "epistemically romantic" philosophers seek.

If the above analysis of intuition-relativity is correct, I want to argue that this still would not affect the possibility of successful conceptual analysis, since the epistemic status of those intuitions is irrelevant to the outcome of conceptual analysis. They are epistemically irrelevant in exactly the same way that hypotheses in science are epistemically irrelevant to the status of the output of the experimental method: namely, good science can be done with false hypotheses. If successful, this argument would not make that output infallible: there are well known issues concerning the epistemic status of the scientific experimental method. Someone might object that it is not meaningful to talk about "the" experimental method as though it were one thing. Yet I will assume that there are interesting commonalities shared by different instances of experimental methods in science which we may focus on in a general way; that there is something we can call the experimental method of science, and it is among the best epistemic methods we have at our disposal, will be a shared assumption given the experimental nature of "experimental" philosophy.

Now that we know the criticism, let us look more closely at the role of intuition in conceptual analysis.

\section{Conceptual analysis and linguistic interpretation}

Conceptual analysis can be understood as an instance of linguistic interpretation (Cohnitz \& Häggqvist 2009:9). When philosophers try to discover the content of say, knowledge or justice, they often begin by outlining how the concept is 
used (in philosophy, or in some other context of discourse) in order to discover the purpose it serves. Using this knowledge, we attempt to extrapolate or create meaning. We do the same thing when we consider the meaning of a linguistic entity. Conceiving of conceptual analysis as an act of interpretation helps to clarify the connection to experimentalism and avoid the problems of intuition skepticism, since the intuitions involved in linguistic interpretation need not be epistemically justified to serve their purpose. In cases of linguistic interpretation, we need to start somewhere to figure out the meaning of an utterance. If we begin with intuitions based on previous experience with a speaker, or a perceived type of speaker, or other contextual features, this will usually speed things up. But we need not begin with accurate information or accurate intuitions. Given the script of a conversation not meant specifically to deceive us, we can discover a great deal about the meaning of unfamiliar terms. This sort of activity is what Quine and Davidson discussed using models of Radical Translation and Radical Interpretation. The intuitions we begin with need not be true or accurate or innate or epistemically privileged because interpretation is a special kind of iterated process, one that can begin with false premises and proceed to true conclusions by repeated application of the same method. Perhaps beginning the process of interpretation with very bad intuitions will drag it out, because we have to throw out the unhelpful intuitions and begin again with others until we find the truth, but it will always be possible to complete, at least in principle. It is one of the very few methods that enjoy this status, the scientific method being another.

Here is a quick example. If my friend gestures towards a nearby harbour and remarks, "What an aggressive chine," I may guess that a chine is a type of boat, an in-harbour manoeuvring technique, a person, or almost anything else. What I know about my friend and human linguistic behaviour generally will constrain my guesses significantly. The resulting conversation will disqualify many possible interpretations and if we continue to discuss chines, I can adjust my questions and guesses without needing to ask what a chine is, until I arrive at the conclusion that it refers to the angle of a boat's hull. From there I can come to learn the differences between hard and soft chines and the advantages of each. This a common experience, especially for those who learn a new language. Is something similar going on when we perform conceptual analysis?

When we set out to analyze a concept in philosophy, we are immediately faced with several different aspects of that concept out of which we identify one (or 
some) to be more interesting than the rest. For example, concerning knowledge we have knowledge that and knowledge how. We could ask whether such a division is a natural division in the concept, for example, by comparing similar ones embodied by the French savoir and connaitre and the Spanish saber and conocer. What we decide to analyze depends on what we want to know. This tells us that some complex concepts must be divided into sub-concepts for easier study, but it also informs us of the different norms that may lie hidden in the concept. Concepts can take the form of exemplars, prototypes, atoms, theories, family resemblances, necessary and sufficient conditions, and all kinds of hybrids (see Margolis \& Laurence 1999, DePaul \& Ramsey 1998). Instead of arguing which of these really captures what we desire from a theory of concepts (pace Prinz 2002), we should ask what these different characterizations of concepts are good for; what kinds of concept use they capture and which concepts types are better for characterizing specific concepts.

Despite being more complex, philosophical conceptual analysis appears essentially similar to the above example with the chine. We provisionally propose some definition for a concept. Then we imagine different cases in which the actual use (or proper use) of a term conflicts with the proposed definition. If by this process we do not reach an acceptable definition, we begin to look for ways of splitting up the concept, or ways of softening the requirement of necessary and sufficient conditions by seeking only exemplars, prototypes, or family resemblances. Supposing that there are correct answers to questions like, "What does $S$ mean when she says $x$ ?" and, "What should $S$ mean when she says $x$ ?", then likewise there will be answers to questions like, "What do we mean when we use concept $x$ ?" and, "What should we mean when we use concept $x$ ?"

Assuming that conceptual analysis is indeed an instance of linguistic interpretation, what evidence is there that the mechanisms which underlie these actions are experimental? Consider what Francis Jacob, a Nobel Prize winning biologist, recently had to say about the practice of science:

In art as in science, the essential thing is to try out. On the one hand, to try out oppositions of colour or harmonizing themes or combinations of words, then to reject what you don't like. On the other hand, to try things; to try ideas, each idea that comes into our heads; each possibility one by one, systematically; then to toss out what doesn't work experimentally and accept what does work, even if that goes against our tastes and biases. Most of the time such attempts lead nowhere. But sometimes the most outlandish experiment happens to open up 
a new rail. The beginning of any research is always a leap into the unknown. It's always after the event that we form judgements on the level of interest of the initial hypothesis. Wrong ideas and outlandish theories abound in science. They are as abundant as bad works of art. (Jacob 2001:118)

Science, for Jacob, is clearly continuous with everyday thinking. When faced with something we want to understand, we begin by "trying out" ideas, combinations of words, and so on, and many of these avenues become closed. What makes science special is the thoroughness with which the new ideas are tested. But, as he says, "The beginning of any research is always a leap into the unknown." Could the same be true of linguistic interpretation and conceptual analysis?

Recent research seems to indicate that it is. Reiner \& Gilbert (2004) asked students to analyze a physical mechanism that behaves in an unexpected way (thanks to some hidden magnets). Given a list of the materials out of which the mechanism was built, different sets of students all followed a common natural method of inquiry: first they constructed various models that could capture what they observed in the mechanism. Then they created what the authors called a "representational space" or in other words, a series of abstract concepts and relations between them, often using pen and paper, that would capture the behaviour of the mechanism as represented in their models. Finally, they tested their abstract models in imaginary worlds using thought experiments.

Reiner and Gilbert argue that all of this is done spontaneously. Physical experiments and thought experiments intertwine seamlessly in the learning process. They claim that "the process of alternating between these two modes-empirically experimenting and experimenting in thought-leads towards a convergence on scientifically acceptable concepts” (p. 1819). According to Reiner and Gilbert, "Conceptual construction starts by negotiating meaning, with self and with others, through 'what-if' questions that turn into imaginary experiments in thought, ultimately being applied to the original physical situation (p. 1821). This sentiment is echoed in Reiner \& Burko (2003), which argues that "as in the physics community, through social discussions of thought experiments, conclusions and thought processes are negotiated, leading to conceptual refinement" (2003:380) (see also Gilbert \& Reiner 2000, Stuart forthcoming, Velentzas \& Halkia 2013).

I highlight these passages which focus on thought experiments because of their use of the imagination. In the process of conceptual refinement, both students and experts have been documented using imaginary worlds to invent and refine hy- 
potheses, in many different problem solving scenarios (see for example, Stephens \& Clement 2006, Clement 2009, Kosem \& Özdemir 2014).

Perhaps it is not far-fetched to claim that everyone, not just students of science, learn to build and evaluate models to invent, evaluate and refine new concepts in a way that draws on general knowledge about the world and individual experience, using the imagination. And this is precisely what we should expect if linguistic interpretation is in some sense an experimental method.

If this is true, we should discuss how conceptual analysis works by discussing the mechanisms that underlie it. We could begin with the input from the imagination, since hypotheses in science and proposed definitions in conceptual analysis both depend on it. Hypotheses are not beliefs; they are imaginings of ways the world could be. What makes a belief good or bad is whether it is true or false. This is not the case with an imagining. For example, my imagining an empty soda can on the dark side of the moon is not better (qua imagining) if there is in fact an empty soda can there.

What does make one imagining better than another? The answer to this depends on what we want to do with the imagining. Perhaps we want to devise an imagining that shows us an example of pure altruism. In this case, reading A Tale of Two Cities might be better than watching a children's cartoon. A more common and general aim is to provide a counterexample to a modal claim, and examples of these abound in science and philosophy (see Cohintz 2003, Häggqvist 1996, Sorensen 1992). Better imaginings will serve their purpose faster and more efficiently, or they will have wonderful consequences. But they need not be true. Christopher Columbus had a hypothesis about a route to India, and it was mistaken. But it was still eminently useful when tested (Lakatos 1976:14). The same considerations hold for scientific hypotheses. Atomism, for example, was important as a metaphysical hypothesis in Ancient Greece, but it was not a good scientific hypothesis until much later. And the phlogiston-theory was a good hypothesis although it was false, because it was fruitful, testable and had a certain degree of explanatory power. (For an argument against the use of the imagination in philosophy, see Thagard 2014. For a defence, see Stuart 2014).

In the case of science, conceptual analysis, and linguistic interpretation, we propose judgments which are then in some sense, tested. In science, these judgments are called hypotheses, and in conceptual analysis and linguistic interpretation they may be called intuitions. In all cases, they rely heavily on the imagi- 
nation, and they appear at many stages of inquiry, even in testing. Furthermore, they need not be true or even formed reliably. No one is surprised or distraught that many or even most scientific hypotheses are incorrect as descriptions of the world, because science has a method for screening these out. Likewise, we should not be concerned that many or most of our intuitions concerning the referents of philosophical concepts are incorrect. Nevertheless, to justify the use of intuitions which are spontaneous and stem in the imagination in conceptual analysis, a philosophical account is necessary.

\section{Epistemological considerations}

Intuitions are involved as part of the guessing process we adopt on the way to understanding linguistic actions and events. Your friend asks if you would like to go to the restaurant across the street. But you know the street well and there is no restaurant there. You immediately have an intuition that she means the jazz bar, which does not serve food. Perhaps you have this intuition because your friend loves jazz, and the music has just now become audible. This intuition becomes your working assumption concerning the meaning of the term "restaurant" in this context, until it is confirmed or denied.

I propose to relate the epistemology of intuitions like these and the roles they play in linguistic interpretation to hypotheses and their roles in science. As Jacob said above, hypotheses are leaps into the unknown, and can be bad or even outlandish. In science they are found in all levels, from experimental, for example, in planning an experiment, to the most theoretical, for example, in dealing with anomalies or developing new formalisms. Leaving aside the exact sciences, hypotheses are never ultimately proven or disproven: they remain open to contradiction or vindication by future experience. The two things most important for my purposes is that they are not used as proof or evidence, and while they are being tested they are not true or false. We should oppose them to ideas, beliefs and commitments which are in this analogy like theories-put forth as candidates for knowledge. Extending this analogy, the goal of interpretation is the meaning of a term, including its intension, extension, relation to other terms and normative profile. The end goal of scientific investigation is something like accuracy or truth, but the more common achievement, which is taken to be a sign of a successful investigation, is what Francis Bacon called "power over nature." If I 
introduce a new term in discourse, I will be satisfied that you have understood it at least partially when you can use the new term in conversation to achieve your ends. Likewise, we understand a phenomenon in science at least partially when we can use it to achieve our ends. These practical abilities are signs of success, and are therefore epistemologically significant. In science, the iterated process of hypothesis, test and theoretical revision is well-known (see for example, Lauden 1973, Peirce 1898). Hasok Chang has coined the term "epistemic iteration" to refer to the scientific process in which "we start by adopting an existing system of knowledge, with some respect for it but without any firm assurance that it is correct; on the basis of that initially affirmed system we launch inquiries that result in the refinement and even correction of the original system. It is this self-correcting progress that justifies (retrospectively) successful courses of development in science, not any assurance by reference to some indubitable foundation" (2004:6). In science, we always have multiple hypotheses being developed at once, if for no other reason than underdetermination of theory by evidence. "Accepting plurality means accepting imprecision, which we can actually afford to do in quite a few cases, with a promise of later tightening” (Chang 2004:158). This "later tightening" consists in empirical testing, calibration of measurement devices, and refinements of cogency and applicability (p. 234). If the analogy to linguistic interpretation is to hold, there must be a tightening process analogous to the one in science.

I would like to argue that Donald Davidson's "principle of charity" could be seen as one such tightening mechanism. Davidson was not the first to propose a principle of charity, but his is perhaps the most influential account (see his 2001a, 2001b, 2005). For Davidson, the principle of charity is not one thing; it is an umbrella term that covers many different and complementary constraints. This group of constraints makes possible successful communication within reasonable time periods. By successful we do not mean flawless: we make mistakes and will be wrong about many of the beliefs and meanings we attribute. Here is Davidson's account.

We must know both the meaning of someone's utterance and their relevant underlying beliefs and their propositional attitudes (believing, doubting, fearing, etc.) if we want to understand their utterance. However, we can guess some of these elements if we know the others. For example if I say "The World Cup is my favourite sporting event" and you know what this sentence means and that 
I believe it, then you will be able to surmise some of my beliefs about soccer. Likewise, if you know my beliefs about soccer and tournaments, you can garner an idea of what the sentence "The World Cup is my favourite Sporting Event" means when I point to the match schedule and I jump up and down clapping my hands, even if I utter the sentence in a language with which you are unfamiliar. But how can you understand my meaning if you do not know either my relevant beliefs, attitudes, or the meaning of my words? This is Davidson's famous case of Radical Interpretation. Here, the key is the propositional attitude of assertion. Davidson thinks we can easily discern this without help from either meaning or belief. If you can tell what someone holds true (or seems to hold true) you can make and test hypotheses for what they mean, and since these attributions will be constrained by certain factors, you can tighten your guesses until you find the correct theory of meaning. The principle of charity explains the way we do this guesswork. It tells us that we superimpose our logic on the speaker, posit events and objects as the ontology of our shared realities (known to both speaker and interpreter) and assume that the speaker's beliefs are mostly true. And we do not just assume them to hold mostly true beliefs; we try to maximize the truth of their beliefs, whenever possible. If I hear you say, "I saw the Grand Canyon flying to California" there are at least two ways to understand this, and you can bet I will not select the option which attributes to you the belief that canyons can fly. While it is not necessary that any specific belief of our speaker be true, his or her beliefs must be true on the whole, because you could not interpret someone who was in systematic error (that is, in error about everything). You could not even disagree with them. Given the way a speaker uses their words and this principle, we can create a theory of meaning for a speaker that could provide in advance the meaning of every possible utterance they might make, by recursion and composition.

However, using a principle of charity that maximizes the truth of your speaker to provide an account of meaning is not without its critics. Analysing some criticism is a good way to explore and update Davidson's principle of charity as an epistemological tool analogous to the method of scientific experimentation. I will focus on the influential criticism of Timothy Williamson.

Williamson argues that any principle of charity that "crudely maximizes true belief" (2004:139) will often recommend incorrect attributions. If I believe many things that are false about $X$ but true about $Y$, it would seem that such a principle 
would recommend that my interpreter ascribe $Y$ as the object of my $X$-utterances and beliefs so as to maximize the number of true beliefs that I hold, regardless of my intention that they be about $X$. We would like to think that some causal history between $X$ and myself is what makes my thoughts have $X$-content, but why? Williamson says it is because causal history often implies past perceptual experience, which is a "channel" for knowledge (p. 140).

I bring up this worry because a similar objection is levelled at conceptual analysis from experimental philosophers, mentioned at the start. Namely, without an objective perspective on knowledge or justice themselves, we do not know whether we are analysing the same thing when different groups of people analyse their versions of these concepts. That is, our tightening procedure does not tighten enough.

Here is an example from Williamson. A psychic makes a prediction about the life history and personality of Santiago. It turns out that this life story and personality more accurately describe a third person, say, Nico. According to Williamson, Davidson's principle recommends that we attribute all of the psychic's beliefs about Santiago's character traits and history to Nico and not Santiago, since this will make more of our psychic's beliefs and utterances true. Since we know that the physic actually intends to have their utterances be about Santiago, and Davidson's principle forces us to attribute them to Nico, we have a reductio against Davidson's account. It is because of the causal (in this case visual) connection between the psychic and Santiago that we still take his or her beliefs and utterances to be about Santiago, even though they are truer of Nico.

And the same could be true about conceptual analysis. Making our own beliefs come out true and consistent would not guarantee that they refer to the right things, or even that such things exist and we can refer to them.

Another example concerns ascribing knowledge of quantum physical laws to people from the Stone Age, since this will help maximize the truth of their beliefs. These ascriptions do not occur on Williamson's account since we need to have a knowledge-channel (or causal connection) between the speaker and his or her objects of speech in order to ascribe something as the source of their belief. For these reasons, Williamson suggests a knowledge (instead of truth) maximizing principle of charity, which relies on being in the relevant position to know something. 
According to Williamson, you cannot be in a position to know something unless that something is actually happening (that is, you cannot know that it is raining unless it true that it is). You also need the right kind of causal contact with the object of your utterance or thought. Finally, we also will not ascribe knowledge to people if that ascription would rely on inferences that are not sound.

My reply to this worry is that truth is a simpler concept than knowledge. It is easier to understand and less presumptuous to assume. Davidson calls it "beautifully transparent" (2001b:139). It seems natural to think that "snow is white is true" is equivalent to "snow is white." On the other hand, saying "snow is white is known" makes little sense without a subject that knows, and a context in which that something is known. If we provide a subject for whom "snow is white" is known, then several things might still be meant by such an ascription. To counter on behalf of Williamson, we could argue that "snow is white is true" can also be relativized to a person and context. However, to do so would be to ignore the adage: ex contradictione sequitur quodlibet-from a contradiction everything follows. If we allow truth to be relative to a speaker, then we must admit that, from a higher level, the same sentence can be both true and false. If this is granted, it makes possible the derivation of anything, even absurdities, from a set of beliefs we thought were conservative and rational (for more on this principle, see Priest et al. 1989). So it is unlikely that any account that allows this kind of simple truth relativization will be used by an opponent of Williamson.

Another point for the simplicity of truth is that in philosophical logic it is a much more basic concept than knowledge. Knowledge is usually introduced as an operator, and doing so creates intensional or opaque contexts. If we assume our speakers and audiences share a basic level of rationality, and we also assume that philosophical logic is a reasonably good model of that rationality, then truth is the simpler concept since logic tells us that an understanding of truth is necessary and antecedent to argumentative reasoning, unlike knowledge which creates situations where substitution of co-referential expressions does not necessarily preserve truth. Further, unlike knowledge, truth does not suffer from Gettier cases or the cultural variation effects found by experimental philosophers like Weinberg, Stich, and Nichols. What is simpler is also perhaps more likely to fit into an evolutionary picture of the development of language and interpretive strategies. 
This focus on simplicity might seem strange; after all, Williamson might be providing a more complicated albeit more accurate account, and surely that would be relevant. And in some cases we do seem to attribute knowledge (and not just truth) when we interpret someone. Williamson argues that causal history is the connection between subject and object which opens the channel to knowledge. Whether something is true or false does not matter-what matters is whether there is a causal connection between the subject and some scenario that justifies their knowledge claims. This is appealing, but although he is not credited, Davidson also knew such causal history would be necessary. In fact, it is part of what his charity demands. He says, "[W]e interpret so as to make an agent as intelligible as possible ... finding him right means identifying the causes with the objects of his beliefs, giving special weight to the simplest cases, and countenancing error where it can be best explained" (2001b:152). It is a subtler principle than Williamson gives him credit for, as the causal history requirement falls right out of the rationality constraints. You would not ascribe an object as the source of someone's belief if they had never had any contact with it. And you wouldn't ascribe quantum physical knowledge to people in the Stone Age, either. For much the same reasons as Williamson, then, Davidson's principle explains why we ascribe what we do as the cause or content of people's beliefs or utterances, only if they have had relevant causal contact with them.

Finally, for Williamson, ascribing knowledge to a person means that such a person must have been in the requisite position to know. This means that the proposition known refers to a state of affairs that was actually happening, existing, or was in whatever sense, actual at the time of utterance. In other words, the proposition known is also true, since it matches the world. This means that whenever we ascribe knowledge we are also ascribing truth. So again, Williamson was right to focus on the causal connection, but not about truth being less desirable for charity than knowledge.

Williamson has a second and independent worry: should we agree with Davidson in thinking that the principle of charity is a maximizing process? Since our belief set is infinite (that is, all the beliefs that can be ascribed to any one of us at any time is infinite, because of recursion), and if we think of maximization as a simple, linear process, Williamson is surely right when he objects that maximizing truth is impossible. How do you maximize the amount of anything in an infinite set? An answer is given by Henry Jackman (2003). He argues that charity 
should be seen as applying only to the weighted sum of a speaker's commitments. You can think of the weighing function as analogous to the way we place different values on questions when devising a test. It need not be esoteric. And those beliefs to which we are committed form a set that is not infinite, because it contains only the beliefs to which we would be disposed to assent if queried. (It also contains our implicit presuppositions and assumptions, but these are included insofar as they can be clearly inferred from our actions, so the set remains finite). The heaviest (or core) commitments are those we would fight the hardest to retain in cases of conflict.

To understand the charity we confer to others, Jackman examines the way we interpret ourselves in cases where core commitments conflict. If, in Quinean fashion, we always save those beliefs we treasure the most, then in cases where some core commitments conflict, we will eliminate beliefs on a case-by-case basis by maximization. We do this depending on the level of importance we assign to our commitments. Jackman argues that such a process would naturally go hand in hand with the way we interpret others. Consider a situation in which you take a sip of what you believe is a mug of hot chocolate, and find that it tastes exactly like tea. Now you have a conflict between your belief that your cup contains hot chocolate, your belief that it contains tea, and your belief that the same cup cannot contain tea and hot chocolate at the same time. This conflict may be dealt with in various ways, but it is much more likely that you will give up the belief, for example, that your drink is hot chocolate, than your belief in the law of noncontradiction, or your belief that hot chocolate does not turn into tea without some serious chemical tampering. This is a simple example where maximization is used, to show that such a process is uncontentious as far as the maximization component is concerned.

If the application of Jackman's idea to this context is correct, this adds to the above defense of Davidson's principle of charity. Namely, if the object of our maximization is the weighted sum of commitments held by the speaker, then having a causal history with the cause of the belief or utterance will certainly make some beliefs heavier than others in meaning ascriptions. This helps to show that being in a position to know will be important for the way that we maximize truth, without showing that knowledge is what should be maximized. Being in a position to know is important for the practice of interpretation; it figures into the way we do it. 
If the process of maximizing truth applies to the weighted sum of a speaker's commitments, and if we are also trying to minimize the amount of unexplained error, then we will usually be maximizing knowledge as well. Especially if Jackman is correct that "Capturing the interpretee's perspective on the world ... involves trying to understand the interpretee as she would, ideally, understand herself” (2003:161), because figuring out which beliefs the interpretee weighs the heaviest, will likely yield the beliefs that the interpretee feels she knows. This account is consistent with the results of psychological studies in empathy, which show that those who attempt to think like others really do understand them better (see Ickes 2003, Stueber 2006), and it also coheres with studies that show sociopaths have difficulty communicating because their ability to see things as others do is reduced (see Baron-Cohen 2011, Meffert et al. 2013, Skeem et al. 2011).

I do not deny that knowledge maximization is part of linguistic interpretation. But the simplicity and fundamentality of truth for interpretation suggests at least a logical and temporal order to the way we apply the principle of charity. First, we ascribe rationality, then truth, and then knowledge. These three levels will be separated in time because the psychological constraints that apply to each are different in terms of their respective strengths, and because there are more or less ways to complete each operation. There are very few ways to satisfy the rationality constraint, but there are more options in satisfying the truth constraint, and even more in maximizing knowledge. Since more and more conscious thought will be necessary to complete the latter requirements, they should take longer to complete, hence the chronological nature of the principle of charity. This demands empirical testing. For now, however, I will merely add a few more theoretical considerations.

Let us consider again the urgency of each type of constraint, beginning with rationality. Davidson says, "We have no choice ... but to read our own logic into the thoughts of a speaker" (2001b:149). If I had to determine consciously whether a speaker was following rules of logic that were relevantly similar to my own, I would never be able to communicate with anyone. If this were the case, it seems unlikely that language would have developed in the first place. Turning to truth, Jackman says that when we interpret ourselves we must assume the general truth of our weighed set of commitments. To see this, notice that we generally see little difference between our beliefs about the world and the beliefs that we hold true. 
We could not interpret ourselves if we needed to determine the overall truth of our beliefs first. Instead, we merely assume they are true. However, if pressed we admit the unlikelihood that all of our beliefs are true, and we do expect to find some contradiction between them (2003:160). To extend this to our interpretation of others, not only will we generally assume the truth of most of our own beliefs, but we must assume the general truthfulness of someone else's beliefs, because again, if they were in massive error (if most of what they believed was false) they would not make any sense to us. It is easy to imagine talking to someone who thought up was down and alive was dead and real was fake and trees were lampshades, but it is very difficult to imagine understanding them. In this way, we must attribute truth and rationality to a speaker to understand them.

However, do we need to attribute knowledge to a speaker? Imagine someone who had mostly true but unjustified beliefs because they were raised by parents who were experts in creating Gettier cases. We would still easily understand the meaning of his or her words, since they would be talking about the same objects, events and relations with which we are familiar. However, we should not attribute to them knowledge of what they say. And this is the point. Williamson is right that we should take casual histories into account when we interpret others, he is wrong when he says that we should reject truth maximization in favour of knowledge maximization. Let me finish by presenting a case where ascribing knowledge leads to undesirable results.

Imagine you are certain that a mobster has committed murder. He told you he was going to kill Rocco, and shortly after the time specified, the police find Rocco murdered in the manner antecedently specified to you by the mobster. The mobster gloats and reveals that he knows specifics of the crime scene to which no one besides the police and the killer had access. You call the police and he is arrested. The police agree that he is guilty. Yet, there is not enough evidence to put him away (it is your word against his, he has a good lawyer and his alibi is carefully worked out). Suppose you say something true when you say, "That man is guilty." This, however, is not something that you can provide complete justification for, either to a jury of your peers in a court of law, or with absolute certainty to yourself. And this is the problem with knowledge maximization as a part of applying charity: knowledge is intimately linked to justification, which is not something we can maximize. 
In fact, maximizing justification would be dangerous. It might invite overconfidence in ourselves, and lead us to expect radicalism or fanaticism in others. Most of our everyday beliefs, even the true ones, simply are not justified in any robust, skepticism-defeating sense. Williamson could reply that justification is not linked to knowledge this intimately, but I think his use of "positions to know" shows that it is. These positions are meant to justify knowledge ascriptions to a third party, but if we can interpret ourselves, and if knowledge is recursive, then you may only know that you know when you know you are in the requisite position to know, that is, when you know you have enjoyed the right kind of causal connection with the object of your knowledge. That is, when you are justified.

When we interpret a speaker, we apply the principle of charity and maximize the truth of their beliefs, and perhaps their knowledge as well. But without educated guesses concerning what our speaker means, we have nothing on which to work. Such guesses are a necessary first step, although this is not something Davidson focused on. These "guesses" fit the description of "intuition" given by experimental philosophers. That is, they are not themselves justified by anything, and we do not feel any need to justify them; they are not quite beliefs, and they appear seemingly out of nowhere. Finally, the outcomes of interpretation are counterfactually dependent on them. And yet, as we have seen, it is not important if these guesses are good or bad, since the constraints involved in applying the principle of charity are so strong that we are quickly forced from our starting point to converge on a better interpretation.

But we do not always stop when we have interpreted our speaker. Occasionally we ask if that speaker is using his or her terms according to the norms that he or she upholds. This is far more difficult than simply understanding someone's words, and there is evidence that this skill only appears later in life. According to Gilbert \& Reiner (2000:276), students around 9 years of age attribute the same meaning to the phrases "theories which explain phenomena" and "the behaviour of phenomena." At ages of 12-16 years, students can see the difference between true and false explanations, but not until they are about 16 do they fully appreciate that knowledge claims are mostly conjectural. The ability to distinguish between what someone says and what they should say, is hard won. How do students decide what a concept should mean? As we saw above, students often invent imaginary scenarios to test their concepts and inter-conceptual relations. So again, guesses (or intuitions) are a necessary first step in the act of determin- 
ing what a person should mean as opposed to what they do mean. And those intuitions are the material on which to run the method; they do not bear all of the epistemological weight of the method's output.

Let us now turn back to conceptual analysis and see how the principle of charity can be used to defend the charge from experimental philosophy.

Remember there are several aims of philosophical conceptual analysis: specifying and exploring the intension and extension of a concept, its relation to other concepts, and its normative profile. Just as in linguistic interpretation, which has similar goals, charity and intuition are called for in all cases. To determine the extension of a concept we often begin by considering its explicit or implicit definition in the hands of certain individuals (for example, knowledge for Plato or Descartes). We try to adopt these definitions ourselves, and assuming our own standards of rationality, try to maximize the truth of our beliefs. We invent imaginary scenarios in which to test the consistency of those beliefs. Once we have a handle on the problems and possible relations between this concept and others, we try to improve the concept. The point is that in many of the stages of this process, intuitions are involved as raw materials, which do not need to be accurate or true or justified. In this sense, intuitions in conceptual analysis function like scientific hypotheses. And so, only if the scientific method is a bad one, is philosophical conceptual analysis unreliable in principle.

One reply to this line of reasoning is the following. My argument attempts to justify one use of intuition in conceptual analysis. But there are others that are used as evidence, and it is those which are the focus of the Weinberg, Nichols and Stich school of experimental philosophy. For example, if you give me a counterexample to my proposed definition for justice, I might have an intuition that your counterexample is a good one, that indeed it disproves my definition. This sort of intuition is not a preliminary guess used to begin the process of conceptual analysis. Rather, it is the source of justification for this or that conceptual revision.

However, this type of intuition can also be treated as a provisional hypothesis that should be tested. It is nothing but another hypothesis, although it is accompanied with a strong emotional response. But it is not the response that justifies the eventual outcome of the test. Of course, some provisional hypotheses are more attractive, and upon hearing them we think "Yes! That must be the case!" however they later prove false. The reason they seem so attractive is perhaps 
because they highlight a new perceived coherence between what we have, and what we want (see Thagard \& Stewart 2011).

Another objection is that by portraying conceptual analysis as linguistic interpretation, I have likened it once again to reflective equilibrium, since the focus here has been on making others and ourselves rational, consistent, true, and so on. However, applying the principle of charity calls for both coherence and correspondence. Our words have no meaning without interaction with the world and with others, which is why causal connection is one of the constraints in the principle of charity.

There is another important difference between interpretation, conceptual analysis and the scientific method on the one hand, and reflective equilibrium on the other. Reflective equilibrium is a method that has as its goal a very specific end state, and there are rules which we use to proceed to that state given the current state. Namely, proceed in a stepwise manner evaluating the system and its consequences with our intuitions until we achieve coherence. This is not the case with the scientific method or, in my view, conceptual analysis or linguistic interpretation. In general, science progresses from vague to specific, from less precise to more precise, from less mathematical to more mathematical. But these general trends are violated all the time, especially during scientific revolutions. And while many philosophers talk meaningfully about the "end of science", it is not such an end point that drives today's scientific investigations. It is local goals. And the same goes for conceptual analysis. We would like, we suppose, a perfectly clear definition of all human concepts, but that is not what motivates us in our quest to understand knowledge and justice. We have subsidiary aims which are more important. And even concerning individual concepts, we care more about finding a workable definition that is enlightening and useful than we do about the one true definition. I think this is because we recognize that concepts will and should change over time. And the same is true of linguistic interpretation. We would like to have a complete theory of meaning for a speaker, but we never actually try to find one. We use whatever methods we have until we reach a satisfactory understanding of our speaker's utterances. Perhaps we do not try to gain a complete theory of meaning because we know that what a speaker means will change over time, and so a complete theory of meaning is not a realistic end point for us. In each of science, conceptual analysis and linguistic interpretation, we do not contextualize our actions with reference to an end point, and we do not follow a 
simple strategy to get there. So with respect to these important points, conceptual analysis has not been reduced to reflective equilibrium.

The natural question to ask at this point is: well then, what are the sources of evidence for conceptual analysis? There is probably no simple answer to this, because a reliable method does not guarantee knowledge. A valid argument is not necessarily a sound one. Cognitive scientists who study conceptual change focus on the development of categorization schemas in children, undergraduates, scientists, and so on, mapping out complex webs of conceptual connections and simulating them in computers. But the exact way in which experience plays a role in learning and (re)evaluating concepts is not yet known, and this collection is a testament to how complex the problem is. What is necessary is some middle ground between the grand philosophical pictures (rationalism, empiricism, naturalism) of the relation between experience and knowledge, and the work of cognitive scientists and linguists.

To conclude: what I have tried to achieve in this paper is not a direct epistemological justification of the output of conceptual analysis, but merely to provide reasons to believe that the method of conceptual analysis is reliable. If we accept the practices of experimental science and everyday linguistic interpretation, we should also accept the method of conceptual analysis.

\section{References}

Ackermann, R. 1985. Data, Instruments and Theory. Princeton, N.J.: Princeton University Press.

Alexander, J., Mallon, R. \& Weinberg, J. 2010. Accentuate the Negative. Review of Philosophy and Psychology 1: 297-314.

Baron-Cohen, S. 2011. Zero Degrees of Empathy: A New Theory of Human Cruelty. London: Penguin.

Batens, D. \& Van Bendegem, J.P. (eds.) 1988. Theory and Experiment. Dordrecht: Reidel.

Bogen, J. \& Woodward, J. 1988. Saving the Phenomena. The Philosophical Review 97: 303-352.

Cartwright, N. 1983. How the Laws of Physics Lie. Oxford: Oxford University Press. Chang, H. 2004. Inventing Temperature: Measurement and Scientific Progress. Oxford: Oxford University Press. 


\section{References}

Clement, J. 2009. Analogy Reasoning via Imagery: The Role of Transformations and Simulations. In B. Kokinov, K. Holyoak, \& D. Gentner (eds.). New Frontiers in Analogy Research. New Bulgarian University Press.

Cohnitz, D. 2003. Modal Skepticism. Philosophical Thought Experiments and Modal Epistemology. In F. Stadler (ed.). The Vienna Circle and Logical Empiricism: Re-Evaluation and Future Perspectives. Dordrecht: Kluwer.

Cohnitz, D. \& Häggqvist, S. 2009. The Role of Intuitions in Philosophy. Studia Philosophica Estonia 2.2: 1-14.

Collins, H. \& Pinch, T. 1993. The Golem: What Everyone Should Know About Science. Cambridge: Cambridge University Press.

Cook, C., Goodman, N. D., \& Schulz, L. E. 2011. Where Science Starts: Spontaneous Experiments in Preschoolers' Exploratory Play. Cognition 120: 341-349.

Davidson, D. 2001a. Inquiries into Truth and Interpretation. Oxford: Clarendon Press.

Davidson, D. 2001b. Subjective, Intersubjective, Objective. Oxford: Clarendon Press.

Davidson, D. 2005. Truth, Language and History. Oxford: Clarendon Press.

DePaul, M. \& Ramsey, W. (eds.) 1998. Rethinking Intuition: The Psychology of Intuition and its Role in Philosophical Inquiry. New York: Rowman \& Littlefield.

Fehige, Y. \& Stuart, M. 2014. On the Origins of the Philosophy of Thought Experiments: The Forerun. Perspectives on Science 22: 179-220.

Franklin, A. 1986. The Neglect of Experiment. Cambridge: Cambridge University Press.

Franklin, A. 1990. Experiment, Right or Wrong. Cambridge: Cambridge University Press.

Franklin, A. 2002. Selectivity and Discord: Two Problems of Experiment. Pittsburgh: University of Pittsburgh Press.

Galison, P. 1987. How Experiments End. Chicago: University of Chicago Press.

Galison, P. 1997. Image and Logic. Chicago: University of Chicago Press.

Gilbert, J. \& Reiner, M. 2000. Thought Experiments in Science Education: Potential and Current Realization. International fournal of Science Education 22: 265-283.

Goldman, A. 1986. Epistemology and Cognition. Cambridge: Harvard University Press.

Gooding, D. 1990. Experiment and the Making of Meaning. Dordrecht: Kluwer Academic Publishers. 
Gooding, D., Pinch, T. \& Schaffer, S. (eds.) 1989. The Uses of Experiment. Cambridge: Cambridge University Press.

Goodman, N. 1955. Fact, Fiction, and Forecast, Cambridge, MA: Harvard University Press.

Hacking, I. 1983. Representing and Intervening. Cambridge: Cambridge University Press.

Häggqvist, S. 1996. Thought Experiments in Philosophy, Stockholm: Almqvist \& Wiksell International.

Ickes, W. 2003. Everyday Mindreading. New York. Prometheus Books.

Jacob, F. 2001. Imagination in Art and Science. The Kenyon Review 23: 113-121.

Jackman, H. 2003. Charity, Self Interpretation, and Belief. Journal of Philosophical Research. 28: 145-170.

Kosem, S.D., \& Özdemir, Ö. F. 2014. The Nature and Function of Thought Experiments in Solving Conceptual Problems. Science and Education 23: 865-895.

Knobe, J. \& Nichols, S. 2008. An Experimental Philosophy Manifesto. In J. Knobe \& S. Nichols (eds.). Experimental Philosophy. New York: Oxford University Press.

Lakatos, I. 1976. Proofs and Refutations. Cambridge: Cambridge University Press. Latour, B. \& Woolgar, S. 1986. Laboratory Life: The Construction of Scientific Facts. Princeton: Princeton University Press.

Lauden, L. 1973. Peirce and the Trivialization of the Self-Correcting Thesis. In R. N Giere \& R. Westfall (eds.). Foundations of Scientific Method: The Nineteenth Century. Bloomington: Indiana Press.

Machery, E., Mallon, R., Nichols, S., \& Stich, S. 2004. Semantics, Cross-Cultural Style. Cognition 92: B1-B12.

Mallon, R., Machery, E., Nichols, S. \& Stich, S. 2009. Against Arguments from Reference. Philosophy and Phenomenological Research 79: 332-356.

Margolis, E. \& Lawrence, S. 1999. Concepts: Core Readings. London: MIT Press.

Meffert, H. Gazzola, V., den Boer, J. A., Bartels, A. A. J. \& Keysers, C. 2013. Reduced Spontaneous but Relatively Normal Deliberate Vicarious Representations in Psychopathy. Brain 136: 2550-2562.

Peirce, C. S. 1898/1934. The First Rule of Logic. In C. Hartshorne \& P. Weiss (eds.). Collected Papers of Charles Sanders Peirce vol. 5. Cambridge: Harvard University Press.

Pickering, A. 1995. The Mangle of Practice. Chicago: University of Chicago Press. 


\section{References}

Pinch, T. 1986. Confronting Nature. Dordrecht: Reidel.

Priest, G., Routley, R., \& Norman, J. (eds.) 1989. Paraconsistent Logic: Essays on the Inconsistent, München: Philosophia Verlag.

Prinz, J. 2002. Furnishing the Mind: Concepts and their Perceptual Basis. Cambridge: MIT Press.

Reiner, M. \& Burko, L. 2003. On the Limitations of Thought Experiments in Physics and the Consequences for Physics Education. Science and Education 13: 365-385.

Reiner, M. \& Gilbert, J. 2004. The Symbiotic Roles of Empirical Experimentation and Thought Experimentation in the Learning of Physics. International fournal of Science Education 26: 1819-1834.

Skeem, J. L., Polaschek, D. L. L., Patrick, C. J. \& Lilienfeld, S. O. 2011. Psychopathic Personality: Bridging the Gap Between Scientific Evidence and Public Policy. Psychological Science in the Public Interest 12: 92-162.

Sorensen, R. 1992. Thought Experiments. Oxford: Oxford University Press.

Stephens, L. A., \& Clement, J. 2006. Designing Classroom Thought Experiments: What we Can Learn from Imagery Indicators and Expert Protocols. Proceedings of the 2006 Annual Meeting of the National Association for Research in Science Teaching, San Francisco.

Stuart, M. 2014. Cognitive Science and Thought Experiments: A Refutation of Paul Thagard's Skepticism. Perspectives on Science 22: 264-287.

Stuart, M. (forthcoming). Imagination: A Sine Qua Non of Science. Croatian Journal of Philosophy.

Stueber, K. 2006. Rediscovering Empathy: Agency, Folk Psychology, and the Human Sciences. Cambridge: MIT Press.

Swain, S., Alexander, J. \& Weinberg, J. 2008. The Instability of Philosophical Intuitions: Running Hot and Cold on Truetemp. Philosophy and Phenomenological Research 76: 138-155.

Thagard, P. 2014. Thought Experiments Considered Harmful. Perspectives on Science 22: 288-305.

Thagard, P. \& Stewart, T. 2011. The Aha! Experience: Creativity Through Emergent Binding in Neural Networks. Cognitive Science 35: 1-33.

Velentzas, A. \& Halkia, K. 2013. From Earth to Heaven: Using 'Newton's Cannon' Thought Experiment for Teaching Satellite Physics. Science and Education 22: 2621-2640. 
Weinberg, J., Nichols, S. \& Stich, S. 2001. Normativity and Epistemic Intuitions. Philosophical Topics. 29: 429-460.

Weinberg, J., Crowley, J., Gonnerman, C., Swain, S., \& Vandewalke, I. 2006. Intuition \& Calibration. Essays in Philosophy 13: 256-283.

Williamson, T. 2004. Philosophical Intuitions and Scepticism about Judgment. Dialectica 58: 109-153.

\section{Author}

Michael T. Stuart

Institute for the History and Philosophy of Science and Technology

University of Toronto 